\title{
Increased expression of PDGFA and RAF1 in tumor- derived exosomes in human colorectal cancer
}

\section{Zahra Madjd ( $\sim$ Zahra.madjd@yahoo.com )}

Iran University of Medical Sciences https://orcid.org/0000-0001-7329-2583

\section{Somayeh Vafaei}

Iran University of Medical Sciences: Tehran University of Medical Sciences

\section{Marzieh Naseri}

Iran University of Medical Sciences: Tehran University of Medical Sciences

\section{Margot Zöller}

Heidelberg Repatriation Hospital

\section{Leili Saeednejad}

Iran University of Medical Sciences: Tehran University of Medical Sciences

\section{Razieh Karamzadeh}

Royan Institute for Stem Cell Biology and Technology

\section{Yuzhen Gao}

Sir Run Run Hospital Nanjing Medical University

Hadi Ahmadi Amoli

Sina Trauma and Surgery Research Center

Marzieh Ebrahimi

Royan Institute for Stem Cell Biology and Technology

\section{Research Article}

Keywords: Colorectal cancer, Bioinformatics analysis, Tumor-derived exosomes, PDGFA, RAF1

Posted Date: January 28th, 2022

DOl: https://doi.org/10.21203/rs.3.rs-1033894/v2

License: (c) (i) This work is licensed under a Creative Commons Attribution 4.0 International License.

Read Full License 


\section{Abstract}

Background: Overexpression of tumor markers in Extracellular vesicles (EV), especially in tumor-derived exosomes (TDEs), is implicated in metastasis. However, identifying the specific content of Ev's roles in colorectal cancer (CRC) diagnosis or prognosis requires further validation by bioinformatics and clinical investigations.

Methods: We explored molecular markers shared between TDEs and circulating tumor cells (CTCs) in the blood of cancer patients to identify candidate genes involved in CRC metastasis. Common markers were analyzed in gene expression profiles of two studies (GSE31023 and GSE72577).

Results: In blood samples from 20 CRC patients, the expression of candidate genes was assessed by realtime polymerase chain reaction (PCR) in CTC, TDEs, and microvesicles (MVs), and the expression levels were correlated with clinicopathological features. To further confirm, the expression of candidate genes was investigated in exosomes derived from the parental HT-29 colorectal cancer cell line (HT-29-EXOs), and cancer stem cells (CSCs) -enriched spheroids (CSC-EXOs) derived thereof. Gene ontology (GO) analysis suggested platelet-derived growth factor A (PDGFA) and proto-oncogene, Serine/Threonine kinase Raf-1 (RAF1) as new CRC candidate markers in CTCs and TDEs. According to real-time PCR, expression of PDGFA ( $P=0.0086)$ and RAF1 $(P=0.048)$ were upregulated in TDEs but significantly decreased $(P=0.0001)$ in MVs. Furthermore, expression in CSC-EXOs $(P=0.0004)$ was increased compared to HT-29-EXOs.

Conclusion: PDGFA and RAF1 mRNA are higher in CSC-EXOs than in HT-29-EXOs, which correlates with higher expression in CSC than the primary tumor. Notably, as no increase was observed in MVs, PDGFA and RAF1 mRNA appear to be actively recruited into TDE.

\section{Purpose}

Colorectal cancer (CRC) is ranked as third in both incidence and mortality rates among cancers worldwide and the incidence rate is rapidly increasing in developing countries. CRC frequently is diagnosed at the late stages by invasive biopsy techniques (colon/sigmoidoscopy) (1). This invasive histological examination hampers regular preventive medical surveillance and post-surgery monitoring. Hence, shifting to non-invasive methods especially based on blood-born molecular markers could possibly allow for earlier detection of primary tumors as well as recurrence and metastases $(2,3)$. Nucleic acid biomarkers are available in biological fluids, and in several malignancies so-called "liquid biopsies" provided ideal biomarkers for diagnosis and prognosis $(4,5)$. Successful tracing of tumors by liquid biopsies relies on the identification of molecular signatures of circulating tumor cells (CTCs) and cancer stem cells (CSCs), in addition to tumor-derived vesicles such as tumor-derived exosomes (TDEs) and microvesicles (MVs) (6).

A considerable number of CTCs and CSCs separate from primary and metastatic tumor cells, which undergo a sequence of epithelial to mesenchymal transition (EMT) steps, provoking invasion, 
intravasation, circulation, extravasation, pre-metastatic niche preparation, and colonization at secondary sites (7). Single or clustered CTCs circulating to distant sites or "self-seeding" can prolong tumor cell survival and their escape from immune cells by multiple mechanisms $(8,9)$. CTCs, isolated from the circulation, provided valuable information on tumor biology and cancer cell dissemination (10). The most common obstacles are heterogeneity and plasticity of CTC as well as their rarity making detection, enumeration and molecular characterization very challenging (11). CSCs are a subpopulation of CTCs with special characteristics including self-renewal, infinite proliferation and multi-lineage differentiation. CSCs are engaged in carcinogenesis, relapse, and chemoresistance $(12,13)$.

Exosomes, 30-150 nm nanovesicles and microvesicles (100-350 nm), two major subtypes of extracellular vesicles (EVs), are released into the body's fluids, including the blood (14). Tumor-derived EV modulates cellular activities in recipient cells by transferring genetic information from cancer cells. Exosomes are endosomal-derived vesicles, which are secreted at the end of the endocytic pathway, when multivesicular bodies fuse with the plasma membrane (15). Exosomes contain heterogeneous cargoes including lipids, proteins, DNAs, and RNAs (mRNA, miRNA, long non-coding RNA, circular RNA) as well as specific markers like CD9, CD63, CD81, Alix, flotillin-1 and tumor susceptibility 101 (TSG101) (16). TDEs contribute to immunosuppression, inflammation, angiogenesis, and fibrosis and account for organselection of the pre-metastatic niche (17). Notably, exosomes derive from selected microdomains and are actively loaded with their cargo during invagination of late endosomes into multivesicular bodies. Distinct to exosomes, microvesicles bud off/fission directly from the plasma membrane. They are a heterogeneous population, not displaying unique markers (18).

According to the derivation from defined membrane microdomains and the selective cargo recruitment, TDEs could possibly compensate for gaps in knowledge on CTC activities, due to CTC rarity, fragility, and short life, whereas TDEs are abundant, comparably stable, with good enrichment by easy-to-handle isolation procedures $(19,20)$. Nonetheless, the content of TDE has not yet been elaborated in detail.

Based on two studies reporting on common biomarkers in CTCs and EVs (gene expression profile of GSE31023 and GSE72577 from GEO database) and cancer-associated gene searches, we became particularly interested in platelet-derived growth factor A (PDGFA) and RAF1 (Raf-1 proto-oncogene, Serine/Threonine kinase) (20-22).

PDGFA is a proangiogenic factor shown to be essential for tumor metastasis in multiple solid tumor types, including colon (23-25) where high expression was associated with poor survival in the four cohorts of clinical trials (26). High level of PDGFA is also a validated predictor of drug resistance and poor prognosis in CRC patients and plays a crucial role in triggering cancer stemness and maintenance (27). Platelet-derived TGF- $\beta$ and PDGF induce EMT in CTCs and endow migratory and invasive properties allowing to break through the ECM of blood vessels (28).

There are three RAF kinases in human, A-RAF, B-RAF and RAF1 (C-RAF) that are reported to play nonredundant roles. RAF kinases interact with activated RAS, which recruits RAF to the plasma membrane to be activated $(29,30)$. Molecular mechanisms underlying expression of KRAS and its effectors and the 
subsequent RAS/MAPK pathways await further clarification (31). Van et al. showed that KRAS can recruit RAF kinase for activation at the membrane from the cytoplasm (32). Furthermore, RAS-RAF complexation, and RAS-RAF interaction was proven in colorectal cancer (33) but it attracts much more debate in colorectal cancer exosomes. Ras family members have been found in a variety of vesicles (34, 35 ) and Beckler et al were the first to specifically detect KRAS in exosomes (36).

Proto-oncogene RAF1 transduces phosphorylation signals from the cell membrane to the nucleus in sequential activation of MAPK/ERK pathway (also known as the Ras-Raf-MEK-ERK pathway) (34). Silencing or pharmacological inhibition of RAF1 impairs clonogenic and tumourigenic capacity of CRC cells and restores apicobasal polarity and formation of tight junctions in cancer cells (36). RAS mutations are negative predictors of response to anti-EGFR antibodies. Hyperactivation of the RAS-RAF signaling pathway is associated with metastasis, angiogenesis, and poor outcomes of patients in CRC (37). Where the oncogenic RAS activated MAPK and PIJK/AKT pathways are considered the main effectors in treatment resistance $(38,39)$.

In the current research, we approached investigating potential common markers between TDEs and CTCs that are implicated in cancer development and metastasis. The mRNA expression levels of predicted target genes were evaluated by quantitative real-time polymerase chain reaction (qRT-PCR) in TDEs and MVs isolated from 20 plasma samples of CRC patients and 10 healthy donors as control. Expression levels of these markers were also examined in exosomes derived from the HT-29 colorectal cancer cell line (HT-29-EXOs) and HT-29 CSC-enriched spheroids (CSC-EXOs). We aimed to shed light on a possible correlation between candidate exosomal mRNAs expression levels and CRC progression and on the EVsassociated mRNA signature. Confirmation of our hypothesis, that TDEs reflect tumor state and aggressiveness, could hold tremendous potential as a minimally invasive screen and may provide hints towards new therapeutic options.

\section{Methods}

\section{Data Collection and Bioinformatics Analysis}

To obtain candidate genes for CTC and TDE in colorectal cancer, two studies (GSE31023 and GSE72577) were selected (https://www.ncbi.nlm.nih.gov/geo/); the Barbazan et al study contained six cancer and three healthy samples (40) and the Dou et al study encompassed three colorectal cancer cell lines (DLD-1, DKO-1 and DKs-8) and the corresponding TDEs (41). First, we compared markers expressed in all three TDE and CTC, but not the cell lines. The genes common to TDEs and CTCs were selected.

Characteristic biological features of selected genes were assigned according to gene ontology analysis (GO) $(42,43)$ to molecular functions, biology processes and cellular components using EnrichR (amp.pharm.mssm.edu/Enrichr/), STRING (https://string-db.org/). DisGeNET RDF v7.0 (ref: https://academic.oup.com/nar/article/48/D1/D845/5611674) was used to search for diseaseassociated markers, with emphasis on tumor growth. Disease classes were ranked based on the gene- 
disease associated (GDA) score and tumor growth-associated markers significantly above the mean score (0.06198) were included in the network analysis, generated using Cytoscape Version 3.7.1 (44) with ClueGO plugin (http://apps.cytoscape.org/apps/cluego). (45) based on gene ontology (GO) (http://geneontology.org/). and pathways, including Kyoto Encyclopedia of Genes and Genomes (KEGG) (https://www.genome.jp/kegg/). (46), Reactome (https://reactome.org/). (47), and WikiPathways (https://www.wikipathways.org/index.php/WikiPathways). (48). DisGeNET integrates both expert-curated databases with text-mined data, covering information on Mendelian and complex diseases (49). All analyses were performed in the $\mathrm{R}$ programming language to reach common molecular markers between CTC and TDE.

\section{Cell Culture and Generation of CSC-Enriched Spheroids}

The colorectal adenocarcinoma HT-29 cell line was obtained from Iranian Biological Research Center (IBRC). Colonosphere formation was carried out as described (50). Briefly, HT-29 cells were grown to 70$90 \%$ confluence. After washing with pre-warmed phosphate-buffered saline (PBS), cells were detached by trypsin/ EDTA (Gibco, Germany) and single cells were seeded in poly-HEMA (Sigma, USA)-coated plates (low attachment condition) in DMEM/F12 serum-free medium (Gibco, Germany) supplemented with 10 $\mathrm{ng} / \mathrm{ml}$ of recombinant basic fibroblast growth factor (bFGF, PeproTech, USA), human recombinant epidermal growth factor (EGF, PeproTech, USA), 2\% B27 supplement (Gibco, Germany), 2mM L-glutamine (Gibco, Germany), 1\% nonessential amino acid (Gibco, Germany), and 1\% penicillin-streptomycin (Gibco, Germany). The culture medium was supplemented with bFGF, EGF, and 2\% B27 supplement every third day. After ten days, culture supernatant was collected for exosome isolation.

For HT-29 cells culture, exosome-free FBS was obtained after overnight ultracentrifugation of FBS (Gibco, Germany) at $110,000 \mathrm{~g}, 4^{\circ} \mathrm{C}$ (45Ti rotor, Beckman Coulter, Fullerton, California). Cells were cultured in DMEM/high glucose media (Gibco, Germany) supplemented with $10 \%$ exosome-free FBS, $1 \%$ Lglutamine (Gibco, Germany), $100 \mathrm{U} / \mathrm{mL}$ of penicillin, and $100 \mathrm{mg} / \mathrm{mL}$ streptomycin (Gibco, Germany), and maintained at $37^{\circ} \mathrm{C}, 5 \% \mathrm{CO}_{2}$ in a humidified incubator. For exosome isolation, the culture supernatant was harvested at $\sim 90 \%$ confluence.

\section{Clinical Sample Collection}

Peripheral blood samples were collected from $20 \mathrm{CRC}$ patients and 10 healthy controls at Bahman and Firozgar hospitals from 2018-2020 under ethical committee approval. Healthy controls were enrolled from people who underwent a routine health checkup without disease detection. Cell-free plasma was isolated from all blood samples using 2000×g for 10min and suspended in Qiazole (Qiagen, Germany). Samples were stored at $-80^{\circ} \mathrm{C}$. Patient information including gender, age, TNM stage, tumor differentiation was also recorded. 


\section{Exosome Isolation by Ultracentrifugation}

Exosomes were isolated from culture media of the HT-29 cell line, HT-29-derived spheroids and plasma samples from patients and healthy controls using ultracentrifugation. In brief, culture supernatants and plasma samples were centrifuged at $350 \times \mathrm{g}$ for $10 \mathrm{~min}$ and then at $3000 \times \mathrm{g}$ for $10 \mathrm{~min}$ to remove cell debris. To separate MV from other extracellular vesicles, supernatants were centrifuged at $21000 \times \mathrm{g}$ for 20 min and the pelleted microvesicles were resuspended in PBS and stored in $-80^{\circ} \mathrm{C}$. The supernatant was passed twice through ultracentrifugation at $110,000 \mathrm{~g}$ for 120 min (45Ti rotor, Beckman Coulter). The exosome pellets were resuspended in $1 \mathrm{ml}$ PBS or lysis buffer (51).

\section{Scanning Electron Microscopy (SEM)}

Isolated exosomes were fixed in 2.5\% (w/v) glutaraldehyde for 20 min, washed in PBS and were dehydrated using a gradient of ethanol $(60 \%, 80 \%, 90 \%$ and $100 \%)$. The exosomes were dried at room temperature for $10 \mathrm{~min}$ on glass. To make surface conductive, a coating of 2-5 nm gold-palladium alloy was applied by sputtering (SPI-Module Sputtering, Argon as gas for plasma) before imaging by SEM (EM3200, KYKY and SEM, Seron Technology, AIS-2100, Korea).

\section{Dynamic Light Scattering (DLS) and Protein Concentration Measurement of Exosomes}

To determine the size distribution of isolated exosomes, $50 \mu \mathrm{l}$ of exosome samples were added to 950 $\mu \mathrm{l}$ PBS and analyzed by dynamic light-scattering measurements (Malvern, UK). Protein quantification was performed by a Bicinchoninic acid assay (BCA) protein assay (Pierce BCA Protein Assay Kit, Thermo Fisher Scientific).

\section{Western Blot Analysis (WB)}

Lysed samples (in RIPA Lysis and Extraction buffer) were subjected to $12 \%$ sodium dodecyl sulfate (SDS) polyacrylamide gel electrophoresis, transferring the separated proteins to polyvinylidene difluoride (PVDF) membranes (Bio-Rad, Hercules, California). After blocking, blots were incubated overnight with primary antibodies (CD9 (Santacruz, Germany (Cat No. sc-13118)), CD81 (Santacruz, Germany (Cat No. SC-166029)), TSG101 (Gentex, U.S.A. (Cat No. GTX70255)) ; 1:500), followed by a two-hour incubation with secondary antibody (goat anti-mouse, Invitrogen, USA). Enhanced chemiluminescence substrate (ECLTM, Thermo Fisher Scientific, USA) was used as detection reagent.

\section{RNA Isolation and qRT-PCR}


RNeasy Micro Kit from Qiagene (Qiagen Cat No. /ID: 74004) was used to isolate the total RNA from exosomes. To remove genomic DNA contamination, RNA samples were treated with DNase I and then Nanodrop (ThermoFisher Scientific, USA) was used for RNA quantification and the purity was checked by

the A260/A280 ratio. Twenty nanogram of total RNAs were used for reverse transcription (RT) to generate cDNAs using PrimeScript RT Reagent Kit (Takara, Japan). SYBR Green real-time master mix was used for qRT-PCR. The corresponding primers were acquired from SinaClon company (Iran) as follow: GAPDH: 5'AACTTTGGCATTGTGGAAGG-3' $F$ and 5'-CACATTGGGGGTAGGAACAC-3' R. PDGFA: 5'-GCC CAT TCG GAG GAA GAG AA-3' F and 5'- CAG ATC AGG AAG TTG GCG GA -3' R. RAF1: 5'- GGT GAT AGT GGA GTC CCA GC -3' F and 5'- GGT GAA GGC GTG AGG TGT AG -3' R. The expression levels of PDGFA and RAF1 mRNAs were normalized by GAPDH mRNA levels based on the $2^{-\triangle \triangle C t}$ approach (52).

\section{Statistical Analysis}

SPSS software version 22.0 (IBM Corp, USA) was utilized to analyze the data. GraphPad Prism version 8.0 for Windows (GraphPad Software, La Jolla, CA, USA, www.graphpad.com) was used to determine the differences between tumor and normal blood samples. Pearson's $\chi 2$ and Spearman's correlation tests were used to analyze the significance of associations and correlations between PDGFA as well as RAF1 expression and clinicopathological parameters. Kruskal-Wallis and Mann-Whitney $U$ tests were applied for pairwise comparisons between groups. In all parts, quantified data are derived from 20 tumors, 10 healthy and cell line-derived exosomes samples, a $p$-value of $<0.05$ was considered statistically significant. As noted, in the first step, all quantified data was replicated an average of three times.

\section{Ethical Approval}

The research ethics committee of Iran University of Medical Sciences issued (IR.IUMS.REC 1395.9221513203) for this study. All procedures including informed consent before surgery from all participants were in accordance with the abovementioned ethical standards. The Ethics Committee of the Bahman and Firozgar Hospitals approved the use of clinical samples. Besides, the patients/participants provided their written informed consent to participate in this study.

\section{Results}

\section{Bioinformatics Approach to Select Appropriate Genes Involved in Metastasis}

We started searching for upregulated genes expressed in 3 CRC-CTCs (40) and exosomes derived from these CRC lines (TDEs) (41) There have been 410 genes upregulated in CTC and exosomes of these lines (Table S1), with 56 markers overexpressed in TDEs from all three cell lines (Figure 1A and Table S2). These 56 genes included a considerable number of non-coding RNAs, where particular long non-coding 
RNA (InCRNA) TPTE pseudogene 1 (TPTEP1) was significantly downregulated. For the remaining genes, network and enrichment analysis of the corresponding proteins according to clustered genes (kmeans) are shown in Table S3. However, only 4 of the genes expressed in TDEs of the 3 lines were recovered in CTCs, an additional 6 were overexpressed in CTCs and at least two TDEs derived from these lines (Figure 1B and Table S2). Network and enrichment analysis of the corresponding ten proteins are shown in Table1 and Figure 1C and 1D. Next, we searched for tumor growth-associated genes in CTCs and the TDEs of the 3 CRC lines (DisGeNET RDF v7.0 database). From all 1046 diseases-related genes, 425 were tumor growth-associated genes (Table S4) and 92 displayed an above average GDA (gene-disease associated) score. Network and enrichment analysis of the corresponding proteins uncovered 4 proteins, PDGFA, UBEH2, TPTE and YWHAZ that were also shared between CTC and tumor line exosomes and, in addition, RAF1, which clustered with TPTE and YWHAZ. In fact, RAF1, PDGFA and YWHAZ had the most shared tumor growth nodes (Figure S1). Based on the connectivity and its central importance in CRC (5355), RAF1 was included in downstream analysis.

Next, we examined by EnrichR reactome, molecular functions, biological processes and KEGG pathway analysis in CRC TDE- and CSC- including oncogenesis-related genes (Table S3). The analysis of cellular component, molecular functions and biological processes of our selected genes were associated with apoptotic, PI3K-AKt signaling pathway and cell cycle sequentially, substantiating that we had depicted the most relevant biomarkers particularly for metastasis and stemness in CTCs and EVs. Besides, by using the above-mentioned tools, we generated the significant related go-terms for RAF1 and PDGFA genes shown in Table S5 and Figure 2. To confirm this hypothesis, the expression of these two candidate genes, where one should keep in mind the association between RAF1 with TPTE and YWHAZ, was assessed and compared in exosomes derived from the serum of $20 \mathrm{CRC}$ patients and 10 healthy donors.

\section{Patients' Characteristics}

The study comprised blood samples from twenty patients and ten healthy volunteers. Clinical data from all patients were recorded. The mean age of patients whom TDEs were isolated were 59 years (SD = 12.48, range 29-81) and whom MVs were isolated were 59 years $(S D=13.08$, range 31-81). The mean age of healthy volunteers were 60 years $(S D=14.79$, range $25-90) ; 6(60 \%)$ of them were aged $\leq 60$ years and $4(40 \%)$ were aged $>60$. All of the clinicopathological details were indicated in Table 2.

\section{Characterization of Isolated Exosomes}

TDEs and MVs were isolated from plasma samples of CRC patients and healthy donors through ultracentrifugation. SEM revealed TDEs and MVs presenting a homogeneous, round morphology (Figure $3 A$ and B) with a Z-average of 133.7 and 920 , and a size range of $88.26 \pm 10.76 \mathrm{~nm}$ and $644 \pm 49 \mathrm{~nm}$, respectively, as determined by dynamic light scattering (Figure $3 \mathrm{C}$ and D). In addition, HT-29-EXOs and CSC-EXOs also displayed round morphology in SEM imaging (Figure 3E and F) and consisted of homogeneous vesicles with a Z-average of 131.2 and 102.8, and a size range of $91.53 \pm 9.65$ and $79.53 \pm$ 8.46 for HT-29-EXOs and CSC-EXOs, respectively (Figure 3G and H). Western blot revealed TSG101, 
CD81 and CD9 exosomes surface markers expression in all three exosome preparations, whereas in the negative control; calnexin (CANX) was not detected (Figure 4A and B).

\section{Increased mRNA Expression levels of PDGFA and RAF1 in CRC Patients' TDEs}

The nonparametric Kruskal-Wallis and Mann-Whitney $U$ tests were utilized to measure the differences between the median mRNA PDGFA and RAF1 expression levels in TDEs from CRC patients compared to the healthy control group. The results showed statistically significant differences of PDGFA and RAF1 between CRC patients and healthy controls ( $P=0.0086$ and $P=0.048$, respectively) (Figure 5A and $\mathrm{B}$ ). The median mRNA expression level of PDGFA and RAF1 was 5.95 and 1.50, respectively. In addition, the median mRNA expression level of their healthy controls was 0.80 and 0.85 , respectively. Moreover, Spearman's correlation analysis revealed that the expression pattern of PDGFA and RAF1 genes was strongly positively correlated with each other's (Spearman's rho, $P=0.0084$ ) in TDEs (Figure 5C). The results of the Mann-Whitney $U$ test also showed a statistically significant difference in the median level of RAF1 mRNA expression between patients' ages $(p=0.05)$. Pearson's $\chi 2$ test also revealed no statistically significant association between the mRNA expression levels of PDGFA and RAF1 in TDEs and clinicopathological characteristics, summarized in Table 3.

\section{Decreased mRNA Expression levels of PDGFA and RAF1 in CRC Patients'-Derived MVs}

Our findings revealed that PDGFA and RAF1 expression levels were decreased in MVs derived from CRC patients compared to the healthy control group ones_(all, $P=0.0001$ ) (Figure 6A and $\mathrm{B}$ ). The median mRNA expression level of PDGFA and RAF1 in CRC Patient and healthy controls-derived MVs were as follows: 0.22 and 0.10 (tumor), 0.95 and 1.0 (healthy), respectively. As described for exosomes, downregulated expression of PDGFA and RAF1 genes in MVs correlated to each other (Spearman's rho, $P=0.0029$ ) (Figure 6C). Pearson's $\chi 2$ test also exhibited no statistically significant association between mRNA expression levels of PDGFA and RAF1 in MVs and clinicopathological parameters that are summarized in Table 4. The results of Real-Time PCR did not reveal any statistically significant differences in the median level of PDGFA and RAF1 mRNA expression with TNM stage and tumor differentiation in TDE (Figure 7A-D) and MVs (Figure 7E-H). The results show that there was no statistically significant association between our groups.

\section{High PDGFA and RAF1 Expression in CSC-EXOs Compared to Parental HT-29-EXOs}


To further evaluate PDGFA and RAF1 expression levels in exosomes from CSC or differentiated tumor cells phenotypes, CSC-derived(56) exosomes (CSC-EXOs) from CSC-enriched spheroids were compared to those derived from the parental cell line (HT-29-EXOs). RT-PCR analysis revealed upregulated expression of both molecules in CSC-EXOs compared to HT-29-EXOs ( $P=0.0004)$ (Figure $8 \mathrm{~A}$ and $\mathrm{B}$ ).

\section{Discussion}

CRC metastases arise from disseminated cancer cells; their settlement being suggested to be dictated by $\operatorname{TDEs}(57,58)$. In view of the inefficacy of current therapeutic protocols in metastasis prevention, detection and functional characterization of metastasis-specific biomarkers are urgently warranted (59).

EMT and stemness have been extensively investigated in CTC (60), where subsets enriched in CSC were of particular interest (61), as an improved understanding of the EMT/CTC/CSC connections may uncover yet unknown pathways of tumor progression and possibly provide hints towards novel therapeutic targets (62).

Besides CTC/CSC, TDEs contribute to EMT, angiogenesis and tumor progression. In addition, TDEs carry selected mRNAs that are shuttled in the CRC microenvironment (63), potentiating cancer progression and affecting CRC patient's prognosis $(64,65)$. TDEs also suppress immune responses, promote immune evasion and increase drug/ chemotherapy resistance $(66,67)$. The steadily increasing interest in CTC and TDE biomarkers in relation to tumor metastasis is forced by high-throughput analyses, which allow for simultaneous identification and quantification of multiple mRNAs. Novel bioinformatic tools facilitate integration of this multitude of genes into functional networks (68).

We used bioinformatic tools to search for molecular markers shared between CTCs and TDEs in CRC. For EVs isolation we choose ultracentrifugation, considered the gold standard for exosome isolation (69). Expression levels of markers, including PDGFA and RAF1, shared by either CTC and TDE or serum-derived TDEs and MVs were evaluated by RT-PCR. To further validate the engagement of TDE-derived PDGFA and RAF1 in the CSC phenotype and characteristics, their expressions were investigated in HT-29-EXOs compared to CSC-EXOs.

Our results indicate increased expression of both PDGFA and RAF1 in TDEs of CRC patients compared to healthy controls. Unexpectedly, expression of both PDGFA and RAF1 was decreased in MVs from CRC patients compared to healthy controls. Notably, PDGFA and RAF1 expressions were correlated in both TDEs and MVs. Low recovery of PDGFA and RAF1 in MVs is in line with MVs originating from budding membrane domains. However, this does not explain lower recovery than in healthy donors' MV. One possible mechanism could be regulation by non-coding RNA, which requires further exploration as we excluded noncoding RNAs from our analysis. Instead, molecular packaging named selective cargo may well contribute to higher PDGFA and RAF1 recovery in TDEs, where besides active recruitment, silencing of counter regulatory elements can presently not be excluded. Finally, PDGFA and RAF1 mRNA is higher in CSC-EXOs than in HT-29-EXOs indicating their potential correlation with the CSC phenotype. 
Thus, with all caution, we assume a possible correlation between increased RAF1 and PDGFA expression in exosomes with tumor progression. This study is the first report touching the increased expression of RAF1 and PDGFA in exosomes derived from CRC patients and CSC-EXOs compared to healthy donor and HT-29 parental-derived exosomes (HT-29-EXOs). Since exosomes content reflects the condition of cells of origin and can lead to modulation in recipient cells by transferring their cargo, as well as based on accumulating evidence of the role of increased expression of RAF1 and PDGFA in tumor progression (invasion, angiogenesis and EMT), we assume some possible correlation between increased $R A F 1$ and PDGFA expression in exosomes with tumor progression.

Accumulating evidence supports that PDGFA is an important mediator of EMT that contributes to cancer invasion and angiogenesis. Overexpression of PDGF-D showed EMT promotion in prostate cancer cells (70). The crosstalk between PDGF and EMT-related signaling pathways, such as the nuclear factor $\mathrm{k}$ light-chain-enhancer of activated $\mathrm{B}$ cells $(N F-K B)$ and chemokine ( $\mathrm{C}-\mathrm{X}-\mathrm{C}$ motif) receptor 4 (CXCR4), further strengthens $P D G F$ playing an important role in EMT. Interestingly, in a study on hepatocellular carcinoma (HCC), PDGF was hypothesized to be involved in TGF- $\beta$-induced EMT of metastasizing cancer cells (71). Additional studies on the TGF- $\beta$ enhanced expression of PDGF and PDGFR via activation of $\beta$-catenin and the signal transducer and activator of transcription 3 (STAT3) (72). However, it should be mentioned that unsupervised use of anti-PDGF could potentially promote tumor invasion and metastasis, stressing dosedependence of the molecular mechanism (73). A study on rectal cancer indicated that mRNA expression of PDGFA was decreased following anti-PDGF treatment and pointed towards PDGFA expression being also associated with drug resistance (74). Moreover, in line with our study, expression was up-regulated under hypoxia as well as in the CSCs and high PDGFA expression was associated with poor overall survival $(75,76)$. Signaling mostly proceeded through the EGF-STAT3 pathway with increased levels of LGR5, and participation of the Wnt signaling pathway in EGFR-positive CRCs. Also, in line to our study, RTPCR confirmed increased PDGFA levels in both HCT-116-CSCs and HT-29-CSCs (27). Our study extends those findings towards the important recovery in TDEs and even more pronounced in CSC-EXOs, which allows for the transfer into target cells.

$R A F 1$ play a carcinogenic role especially in angiogenesis process (38). Moreover, targeting of $R A F 1$ by miR-7-5p inhibits endothelial cell proliferation. Inhibition of RAF1 kinase activity impairs CRC growth. Furthermore, down-regulation of miR-431-5p as well as up-regulation of FBXL19-AS1 increases RAF1 expression. Thus, FBXL 19-AS1 knockdown-mediated inhibition of lung cancer progression and the expression of angiogenesis associated proteins could be rescued by RAF1 overexpression $(77,78)$.

In summary, in line with these studies, we observed overexpression of PDGFA and RAF1 in exosomes from CRC patients, where overexpressions were associated with poor clinicopathological features. These findings suggest a possible role of TDEs with prometastatic factors, including specific mRNAs, as messengers for primary tumor growth and microenvironment preparation for metastasis.

Additional advantages of mRNA biomarkers deserve discussion. In comparison to DNA, mRNAs provide a solid base for signaling network connectivities. Uncovering signaling networks makes RNAs most 
important in unraveling protein-RNA complexes and allows identifying potential candidates for follow-up work at the protein level including functional studies. Furthermore, due to translational modulation and post-translational modification, protein levels do not necessarily reflect gene expression levels, a problem that can be circumvented by elaborating RNA levels $(79,80)$. Several publications also support the importance of mRNA in CRC. Furthermore, additional publications support the view that both mRNA and protein analysis can confirm each other (81-83). Finally, again in CRC, liquid biopsy-based mRNA evaluation was suggested providing new insights into potential mRNA indicators that may allow avoiding invasive diagnostic operations.

In spite of that, current study had a few limitations, Firstly, our patients' sample size was small requiring future validation in large cohorts of patients' serum-derived TDEs and CSC-EXOs. Secondly, our findings need confirmation at the protein level. This accounts for clinical serum samples as well as for cell culturederived exosomes and for in vivo controls in mouse models. Though our exosome sample sizes, particularly in the clinical cohort, were too small for a comprehensive protein analysis, this will be possible by the restriction to PDGFA and RAF1. Thirdly, the mode of functional activity of PDGFA and $R A F 1$ in CRC requires further elaboration including the clarification of preferential actions at the mRNA or the protein level.

This is important as to our knowledge we were the first describing high PDGFA and RAF1 mRNA expression in TDEs from CRC patients and exosomes derived from CSC-enriched spheroids, exosomes being a prerequisite for transfer into host cells, may play potential roles in tumor growth and progression. Additionally, serum-derived TDEs would present an easily accessible, non-invasive tool for early diagnosis, prognosis and therapy control.

\section{Conclusion}

Based on our results, PDGFA and RAF1 mRNA are higher in CSC-EXOs than in HT-29-EXOs which correlates with higher expression in CSC than the primary tumor. Notably, as no increase was observed in MVs, PDGFA and RAF1 mRNA appear being actively recruited into TDE. In view of the suggested importance of $P D G F A$ and $R A F 1$ expression in CRC prognosis, further validation has high priority in future plan.

\section{Future Perspective}

large-scale sample analyses are required to unequivocally sustain the superior validity of mRNA enrichment in CRC TDEs. Moreover, next generation sequencing should focus on blood sample-derived CTCs and TDEs of CTC to unravel a comprehensive signature of metastasizing CRC. Completion of these studies may prove serum-derived TDEs as a highly reliable tool for CRC prognostication and patient management.

\section{Abbreviations}


BCA: Bicinchoninic acid assay

bFGF: basic fibroblast growth factor

CAPZA2: Capping Actin Protein of Muscle Z-Line Subunit Alpha 2

CRC: colorectal cancer

CSC-EXOs: HT-29 CSC exosomes

CSCs: cancer stem cells

CTCs: circulating tumor cells

CXCR4: chemokine (C-X-C motif) receptor 4

DLS: dynamic light scattering

EGF: human recombinant epidermal growth factor

EGF-STAT3: Epidermal growth factor signal transducer and activator of transcription 3

EMT: epithelial to mesenchymal transition

EVs: Extra cellular vesicles

GO: Gene ontology

GSEA: Gene set enrichment analysis

HCC: hepatocellular carcinoma

HT-29-EXOs: HT-29 colorectal cancer cell line exosomes

IBRC: Iranian Biological Research Center

LDLRAP1: Low Density Lipoprotein Receptor Adaptor Protein 1

LGR5: Leucine-rich repeat-containing G-protein coupled receptor 5

MAPK/ERK: Ras-Raf-MEK-ERK pathway

MVs: Microvesicles

NF-kB: nuclear factor K-light-chain-enhancer of activated B cells

NPTN: Neuroplastin 
PBS: phosphate-buffered saline

PDGFA: Platelet Derived Growth Factor Subunit A

PPP3R1: Protein Phosphatase 3 Regulatory Subunit B, Alpha

PVDF: polyvinylidene difluoride

RAF1: Raf-1 Proto-Oncogene, Serine/Threonine Kinase

RNF11: Ring Finger Protein

SDS: sodium dodecyl sulfate

SEM: scanning electron microscopy

TDEs: tumor-derived exosomes

TPTE: Transmembrane Phosphatase with Tensin Homology

TSG101: Tumor Susceptibility 101

UBE2H: Ubiquitin Conjugating Enzyme E2

WB: western blot

Wnt: Wnt Family Member 1

YWHAH: Tyrosine 3-Monooxygenase/Tryptophan 5-Monooxygenase Activation Protein Eta

YWHAZ: Tyrosine 3-Monooxygenase/Tryptophan 5-Monooxygenase Activation Protein Zeta

\section{Declarations}

\section{Ethics approval and consent to participate}

The Research Ethics Committee of Iran University of Medical Sciences issued IR.IUMS.REC 1395.9221513203 for this study. All procedures, including obtaining informed consent from each human participant before surgery, were in accordance with the above-mentioned ethical standards.

\section{Consent for publication}

The signedconsentensured that the publisher has theparticipate and author'spermissiontopublishthe relevant Contribution.Besides, all of the included studies data were used by reference citation and all of the authors consent to publication. 


\section{Availability of Data and Materials}

Data sharing is not applicable to this article as no new data were created or analyzed in this study. Analyzed data are openly available in [repository name at http://doi.org/[doi] and reference number.

\section{Competing Interests}

The authors whose names are listed certify that they have NO affiliations in any organization or entity with any financial interest and non-financial interest in the subject matter or materials discussed in this manuscript.

\section{Funding}

This study is part of a PhD thesis in Department of Molecular Medicine and mainly was funded by Iran University of Medical Sciences (number: 96-01-87-30129).

\section{Author's Contributions}

ZM, MEandSV, conceived the presented idea. SVcollected the blood samples, run the experimental laboratory tests, analyzed and interpreted data and wrote the first draft. ZM and ME developed, revised and approved the theory.MN performed cell culture and spheroid formation assay. SV performedcritical revisions of the first draft and verified the concept. YG andRKhelped in bioinformatics data analysis. HA, colorectal surgery specialists who provided patients' tumor sample and their data. All authors read, approved and discussed the results and contributed to the final manuscript.

\section{Acknowledgements}

We are grateful our colleagues in Oncopathology Research Center, Iran University of Medical Sciences for their help and also we would like to thank Dr. Faezeh Shekari for her expertise and assistance in this study.

This project has been conducted by a grant from Cancer Research Center of Cancer Institute of Iran (Sohrabi cancer charity, Grant No: 37353-202-01-97) and also by a grant from Royan Stem Cell Technology Company (RSCT96030202).

\section{References}

1. Bray F, Ferlay J, Soerjomataram I, Siegel RL, Torre LA, Jemal A (2018) Global cancer statistics 2018: GLOBOCAN estimates of incidence and mortality worldwide for 36 cancers in 185 countries. CA 
Cancer J Clin 68(6):394-424

2. Punt CJ, Koopman M, Vermeulen L (2017) From tumour heterogeneity to advances in precision treatment of colorectal cancer. Nat Rev Clin Oncol 14(4):235-246

3. Zhai Z, Yu X, Yang B, Zhang Y, Zhang L, Li X et al (2017) Colorectal cancer heterogeneity and targeted therapy: Clinical implications, challenges and solutions for treatment resistance. Semin Cell Dev Biol 64:107-115

4. Hench IB, Hench J, Tolnay M (2018) Liquid Biopsy in Clinical Management of Breast, Lung, and Colorectal Cancer. Front Med (Lausanne) 5:9

5. Lopez A, Harada K, Mizrak Kaya D, Dong X, Song S, Ajani JA (2018) Liquid biopsies in gastrointestinal malignancies: when is the big day? Expert Rev Anticancer Ther 18(1):19-38

6. Vafaei S, Fattahi F, Ebrahimi M, Janani L, Shariftabrizi A, Madjd Z (2019) Common molecular markers between circulating tumor cells and blood exosomes in colorectal cancer: a systematic and analytical review. Cancer Manag Res 11:8669-8698

7. Katt ME, Wong AD, Searson PC (2018) Dissemination from a Solid Tumor: Examining the Multiple Parallel Pathways. Trends Cancer 4(1):20-37

8. Giuliano M, Shaikh A, Lo HC, Arpino G, De Placido S, Zhang XH et al (2018) Perspective on Circulating Tumor Cell Clusters: Why It Takes a Village to Metastasize. Cancer Res 78(4):845-852

9. Kim MY, Oskarsson T, Acharyya S, Nguyen DX, Zhang XH, Norton L et al (2009) Tumor self-seeding by circulating cancer cells. Cell 139(7):1315-1326

10. Kang Y, Pantel K (2013) Tumor cell dissemination: emerging biological insights from animal models and cancer patients. Cancer Cell 23(5):573-581

11. Lei X, Jonathan S, Yong-Jie L (2015) Circulating Tumor Cells: A Window to Understand Cancer Metastasis, Monitor and Fight Against Cancers. Journal of Cancer Research Updates 4(1):13-29

12. Zhou Y, Xia L, Wang H, Oyang L, Su M, Liu Q et al (2018) Cancer stem cells in progression of colorectal cancer. Oncotarget 9(70):33403-33415

13. Fedyanin M, Anna P, Elizaveta P, Sergei T (2017) Role of Stem Cells in Colorectal Cancer Progression and Prognostic and Predictive Characteristics of Stem Cell Markers in Colorectal Cancer. Curr Stem Cell Res Ther 12(1):19-30

14. Li P, Kaslan M, Lee SH, Yao J, Gao Z (2017) Progress in Exosome Isolation Techniques Theranostics 7(3):789-804

15. Lee Y, El Andaloussi S, Wood MJ (2012) Exosomes and microvesicles: extracellular vesicles for genetic information transfer and gene therapy. Hum Mol Genet 21(R1):R125-R134

16. Kowal J, Arras G, Colombo M, Jouve M, Morath JP, Primdal-Bengtson B et al (2016) Proteomic comparison defines novel markers to characterize heterogeneous populations of extracellular vesicle subtypes. Proc Natl Acad Sci U S A 113(8):E968-E977

17. Fu Q, Zhang Q, Lou Y, Yang J, Nie G, Chen Q et al (2019) Correction: Primary tumor-derived exosomes facilitate metastasis by regulating adhesion of circulating tumor cells via SMAD3 in liver cancer. 
Oncogene 38(28):5740-5741

18. Pan BT, Johnstone RM (1983) Fate of the transferrin receptor during maturation of sheep reticulocytes in vitro: selective externalization of the receptor. Cell 33(3):967-978

19. Gold B, Cankovic M, Furtado LV, Meier F, Gocke CD (2015) Do circulating tumor cells, exosomes, and circulating tumor nucleic acids have clinical utility? A report of the association for molecular pathology. J Mol Diagn 17(3):209-224

20. Shao H, Chung J, Issadore D (2015) Diagnostic technologies for circulating tumour cells and exosomes. Biosci Rep 36(1):e00292-e

21. Fransén K, Klintenäs M, Osterström A, Dimberg J, Monstein HJ, Söderkvist P (2004) Mutation analysis of the BRAF, ARAF and RAF-1 genes in human colorectal adenocarcinomas. Carcinogenesis 25(4):527-533

22. Nie F, Cao J, Tong J, Zhu M, Gao Y, Ran Z (2015) Role of Raf-kinase inhibitor protein in colorectal cancer and its regulation by hydroxycamptothecine. J Biomed Sci 22:56

23. Heldin C-H (2013) Targeting the PDGF signaling pathway in tumor treatment. Cell Commun Signal $11: 97$

24. Paulsson J, Ehnman M, Östman A (2014) PDGF receptors in tumor biology: prognostic and predictive potential. Future Oncol 10(9):1695-1708

25. Xu R, Ji J, Zhang X, Han M, Zhang C, Xu Y et al (2017) PDGFA/PDGFRalpha-regulated GOLM1 promotes human glioma progression through activation of AKT. J Exp Clin Cancer Res 36(1):193

26. Halberg N, Sengelaub CA, Navrazhina K, Molina H, Uryu K, Tavazoie SF (2016) PITPNC1 Recruits RAB1B to the Golgi Network to Drive Malignant Secretion. Cancer Cell 29(3):339-353

27. Cheng CC, Liao PN, Ho AS, Lim KH, Chang J, Su YW et al (2018) STAT3 exacerbates survival of cancer stem-like tumorspheres in EGFR-positive colorectal cancers: RNAseq analysis and therapeutic screening. J Biomed Sci 25(1):60

28. Linnekamp JF, Wang X, Medema JP, Vermeulen L (2015) Colorectal cancer heterogeneity and targeted therapy: a case for molecular disease subtypes. Cancer Res 75(2):245-249

29. Mason CS, Springer CJ, Cooper RG, Superti-Furga G, Marshall CJ, Marais R (1999) Serine and tyrosine phosphorylations cooperate in Raf-1, but not B-Raf activation. EMBO J 18(8):2137-2148

30. Josse R, Zhang YW, Giroux V, Ghosh AK, Luo J, Pommier Y (2015) Activation of RAF1 (c-RAF) by the Marine Alkaloid Lasonolide A Induces Rapid Premature Chromosome Condensation. Mar Drugs 13(6):3625-3639

31. Assi M, Achouri Y, Loriot A, Dauguet N, Dahou H, Baldan J et al (2021) Dynamic Regulation of Expression of KRAS and Its Effectors Determines the Ability to Initiate Tumorigenesis in Pancreatic Acinar Cells. Cancer Res 81(10):2679-2689

32. Van QN, Lopez CA, Tonelli M, Taylor T, Niu B, Stanley CB et al (2020) Uncovering a membrane-distal conformation of KRAS available to recruit RAF to the plasma membrane. Proc Natl Acad Sci U S A 117(39):24258-24268 
33. Tran TH, Chan AH, Young LC, Bindu L, Neale C, Messing S et al (2021) KRAS interaction with RAF1 RAS-binding domain and cysteine-rich domain provides insights into RAS-mediated RAF activation. Nat Commun 12(1):1176

34. McKay J, Wang X, Ding J, Buss JE, Ambrosio L (2011) H-ras resides on clathrin-independent ARF6 vesicles that harbor little RAF-1, but not on clathrin-dependent endosomes. Biochimica et Biophysica Acta (BBA) -. Molecular Cell Research 1813(2):298-307

35. Eng SK, Imtiaz IR, Goh BH, Ming LC, Lim YC, Lee WL (2021) Does KRAS Play a Role in the Regulation of Colon Cancer Cells-Derived Exosomes? Biology (Basel). ; 10(1)

36. Demory Beckler M, Higginbotham JN, Franklin JL, Ham AJ, Halvey PJ, Imasuen IE et al (2013) Proteomic analysis of exosomes from mutant KRAS colon cancer cells identifies intercellular transfer of mutant KRAS. Mol Cell Proteomics 12(2):343-355

37. Liu Z, Liu Y, Li L, Xu Z, Bi B, Wang Y et al (2014) MiR-7-5p is frequently downregulated in glioblastoma microvasculature and inhibits vascular endothelial cell proliferation by targeting RAF1. Tumour Biol 35(10):10177-10184

38. Borovski T, Vellinga TT, Laoukili J, Santo EE, Fatrai S, van Schelven S et al (2017) Inhibition of RAF1 kinase activity restores apicobasal polarity and impairs tumour growth in human colorectal cancer. Gut 66(6):1106-1115

39. Kasper S, Reis H, Ziegler S, Nothdurft S, Mueller A, Goetz M et al (2017) Molecular dissection of effector mechanisms of RAS-mediated resistance to anti-EGFR antibody therapy. Oncotarget 8(28):45898-45917

40. Barbazan J, Alonso-Alconada L, Muinelo-Romay L, Vieito M, Abalo A, Alonso-Nocelo M et al (2012) Molecular characterization of circulating tumor cells in human metastatic colorectal cancer. PLoS ONE 7(7):e40476

41. Dou Y, Cha DJ, Franklin JL, Higginbotham JN, Jeppesen DK, Weaver AM et al (2016) Circular RNAs are down-regulated in KRAS mutant colon cancer cells and can be transferred to exosomes. Sci Rep 6:37982

42. Mi H, Muruganujan A, Ebert D, Huang X, Thomas PD (2019) PANTHER version 14: more genomes, a new PANTHER GO-slim and improvements in enrichment analysis tools. Nucleic Acids Res 47(D1):D419-DD26

43. Harris MA, Clark J, Ireland A, Lomax J, Ashburner M, Foulger R et al (2004) The Gene Ontology (GO) database and informatics resource. Nucleic Acids Res 32(Database issue):D258-D261

44. Shannon P, Markiel A, Ozier O, Baliga NS, Wang JT, Ramage D et al (2003) Cytoscape: a software environment for integrated models of biomolecular interaction networks. Genome Res 13(11):24982504

45. Bindea G, Mlecnik B, Hackl H, Charoentong P, Tosolini M, Kirilovsky A et al (2009) ClueGO: a Cytoscape plug-in to decipher functionally grouped gene ontology and pathway annotation networks. Bioinformatics 25(8):1091-1093 
46. Kanehisa M, Furumichi M, Sato Y, Ishiguro-Watanabe M, Tanabe M (2021) KEGG: integrating viruses and cellular organisms. Nucleic Acids Res 49(D1):D545-Dd51

47. Wu G, Haw R (2017) Functional Interaction Network Construction and Analysis for Disease Discovery. Methods Mol Biol 1558:235-253

48. Martens M, Ammar A, Riutta A, Waagmeester A, Slenter DN, Hanspers K et al (2021) WikiPathways: connecting communities. Nucleic Acids Res 49(D1):D613-DD21

49. Pinero J, Bravo A, Queralt-Rosinach N, Gutierrez-Sacristan A, Deu-Pons J, Centeno E et al (2017) DisGeNET: a comprehensive platform integrating information on human disease-associated genes and variants. Nucleic Acids Res 45(D1):D833-D8D9

50. Eini L, Naseri M, Karimi-Busheri F, Bozorgmehr M, Ghods R, Madjd Z (2020) Primary colonospheres maintain stem cell-like key features after cryopreservation. J Cell Physiol 235(3):2452-2463

51. Taghikhani A, Hassan ZM, Ebrahimi M, Moazzeni SM (2019) microRNA modified tumor-derived exosomes as novel tools for maturation of dendritic cells. J Cell Physiol 234(6):9417-9427

52. Livak KJ, Schmittgen TD (2001) Analysis of relative gene expression data using real-time quantitative PCR and the 2(-Delta Delta C(T)) Method. Methods 25(4):402-408

53. Ji H, Greening DW, Barnes TW, Lim JW, Tauro BJ, Rai A et al (2013) Proteome profiling of exosomes derived from human primary and metastatic colorectal cancer cells reveal differential expression of key metastatic factors and signal transduction components. Proteomics 13(10-11):1672-1686

54. Nie F, Cao J, Tong J, Zhu M, Gao Y, Ran Z (2015) Role of Raf-kinase inhibitor protein in colorectal cancer and its regulation by hydroxycamptothecine. J Biomed Sci 22(1):56

55. Leicht DT, Balan V, Kaplun A, Singh-Gupta V, Kaplun L, Dobson M et al (2007) Raf kinases: function, regulation and role in human cancer. Biochim Biophys Acta 1773(8):1196-1212

56. Vafaei S, Saeednejad Zanjani L, Habibi Shams Z, Naseri M, Fattahi F, Gheytanchi E et al (2020) Low expression of Talin1 is associated with advanced pathological features in colorectal cancer patients. Sci Rep 10(1):17786

57. Fares J, Fares MY, Khachfe HH, Salhab HA, Fares Y (2020) Molecular principles of metastasis: a hallmark of cancer revisited. Signal Transduction and Targeted Therapy 5(1):28

58. Tickner JA, Urquhart AJ, Stephenson SA, Richard DJ, O'Byrne KJ (2014) Functions and therapeutic roles of exosomes in cancer. Front Oncol 4:127

59. Vafaei S, Roudi R, Madjd Z, Aref AR, Ebrahimi M (2020) Potential theranostics of circulating tumor cells and tumor-derived exosomes application in colorectal cancer. Cancer Cell Int 20:288

60. Papadaki MA, Stoupis G, Theodoropoulos PA, Mavroudis D, Georgoulias V, Agelaki S (2019) Circulating Tumor Cells with Stemness and Epithelial-to-Mesenchymal Transition Features Are Chemoresistant and Predictive of Poor Outcome in Metastatic Breast Cancer. Mol Cancer Ther 18(2):437-447

61. Gkountela S, Aceto N (2016) Stem-like features of cancer cells on their way to metastasis. Biol Direct 11(1):33 
62. Agnoletto C, Corrà F, Minotti L, Baldassari F, Crudele F, Cook WJJ et al (2019) Heterogeneity in Circulating Tumor Cells: The Relevance of the Stem-Cell Subset. Cancers (Basel) 11(4):483

63. Wang B, Wang Y, Yan Z, Sun Y, Su C (2019) Colorectal cancer cell-derived exosomes promote proliferation and decrease apoptosis by activating the ERK pathway. Int J Clin Exp Pathol 12(7):2485-2495

64. Conigliaro A, Cicchini C (2018) Exosome-Mediated Signaling in Epithelial to Mesenchymal Transition and Tumor Progression.J Clin Med. ; 8(1)

65. Mashouri L, Yousefi H, Aref AR, Ahadi AM, Molaei F, Alahari SK (2019) Exosomes: composition, biogenesis, and mechanisms in cancer metastasis and drug resistance. Mol Cancer 18(1):75

66. Lafitte M, Lecointre C, Roche S (2019) Roles of exosomes in metastatic colorectal cancer. Am J Physiol Cell Physiol 317(5):C869-CC80

67. Steinbichler TB, Dudas J, Skvortsov S, Ganswindt U, Riechelmann H (2019) Skvortsova, II. Therapy resistance mediated by exosomes. Mol Cancer 18(1):58

68. Medeiros B, Allan AL (2019) Molecular Mechanisms of Breast Cancer Metastasis to the Lung: Clinical and Experimental Perspectives.Int J Mol Sci. ; 20(9)

69. Witwer KW, Buzas El, Bemis LT, Bora A, Lasser C, Lotvall J et al (2013) Standardization of sample collection, isolation and analysis methods in extracellular vesicle research.J Extracell Vesicles. ; 2

70. Kong D, Li Y, Wang Z, Banerjee S, Ahmad A, Kim HR et al (2009) miR-200 regulates PDGF-D-mediated epithelial-mesenchymal transition, adhesion, and invasion of prostate cancer cells. Stem Cells 27(8):1712-1721

71. Liu J, Liao S, Huang Y, Samuel R, Shi T, Naxerova K et al (2011) PDGF-D improves drug delivery and efficacy via vascular normalization, but promotes lymphatic metastasis by activating CXCR4 in breast cancer. Clin Cancer Res 17(11):3638-3648

72. Lahsnig C, Mikula M, Petz M, Zulehner G, Schneller D, van Zijl F et al (2009) ILEl requires oncogenic Ras for the epithelial to mesenchymal transition of hepatocytes and liver carcinoma progression. Oncogene 28(5):638-650

73. Hosaka K, Yang Y, Seki T, Nakamura M, Andersson P, Rouhi P et al (2013) Tumour PDGF-BB expression levels determine dual effects of anti-PDGF drugs on vascular remodelling and metastasis. Nat Commun 4:2129

74. Verstraete M, Debucquoy A, Dekervel J, van Pelt J, Verslype C, Devos E et al (2015) Combining bevacizumab and chemoradiation in rectal cancer. Translational results of the AXEBeam trial. $\mathrm{Br} \mathrm{J}$ Cancer 112(8):1314-1325

75. Zong S, Li W, Li H, Han S, Liu S, Shi Q et al (2017) Identification of hypoxia-regulated angiogenic genes in colorectal cancer. Biochem Biophys Res Commun 493(1):461-467

76. Paulsson J, Ehnman M, Ostman A (2014) PDGF receptors in tumor biology: prognostic and predictive potential. Future Oncol 10(9):1695-1708 
77. Tian H, Yin L, Ding K, Xia YY, Wang XH, Wu JZ et al (2018) Raf1 is a prognostic factor for progression in patients with nonsmall cell lung cancer after radiotherapy. Oncol Rep 39(4):1966-1974

78. Jiang Q, Cheng L, Ma D, Zhao Y (2019) FBXL19-AS1 exerts oncogenic function by sponging miR-431$5 p$ to regulate RAF1 expression in lung cancer.Biosci Rep. ; 39(1)

79. Duan G, Walther D (2015) The roles of post-translational modifications in the context of protein interaction networks. PLoS Comput Biol 11(2):e1004049-e

80. Edfors F, Danielsson F, Hallström BM, Käll L, Lundberg E, Pontén F et al (2016) Gene-specific correlation of RNA and protein levels in human cells and tissues. Mol Syst Biol 12(10):883

81. Koussounadis A, Langdon SP, Um IH, Harrison DJ, Smith VA (2015) Relationship between differentially expressed mRNA and mRNA-protein correlations in a xenograft model system. Sci Rep 5(1):10775

82. Brion C, Lutz SM, Albert FW (2020) Simultaneous quantification of mRNA and protein in single cells reveals post-transcriptional effects of genetic variation.Elife. ; 9

83. Greenbaum D, Colangelo C, Williams K, Gerstein M (2003) Comparing protein abundance and mRNA expression levels on a genomic scale. Genome Biol 4(9):117

\section{Tables}

\section{Table 1}

Main characteristics of the ten proteins recovered in TDEs and CTCs 


\begin{tabular}{|c|c|c|c|c|}
\hline Gene name & Description & $\begin{array}{l}\text { Metastasis- } \\
\text { related }\end{array}$ & $\begin{array}{l}\text { Stemness- } \\
\text { related }\end{array}$ & Main Signaling Pathways \\
\hline PDGFA & $\begin{array}{l}\text { Platelet Derived Growth } \\
\text { Factor Subunit A }\end{array}$ & yes & yes & $\begin{array}{l}\text { Notch1/Twistl pathway } \\
\text { Wnt signaling } \\
\text { related to EGFR and STAT3 } \\
\text { constitutive signaling by aberrant PI3K in cancer } \\
\text { cell proliferation and migration } \\
\text { survival and chemotaxis }\end{array}$ \\
\hline RNF11 & Ring finger protein 11 & unknown & unknown & $\begin{array}{l}\text { related to NFkB and EGFR } \\
\text { essential component of an ubiquitin-editing protein complex }\end{array}$ \\
\hline TPTE & $\begin{array}{l}\text { Transmembrane } \\
\text { Phosphatase with Tensin } \\
\text { Homology }\end{array}$ & yes & unknown & $\begin{array}{l}\text { Pten-related tyrosine phosphatase } \\
\text { signal transduction pathway of endocrine or spermatogenic } \\
\text { functions of the testis }\end{array}$ \\
\hline PPP3R1 & $\begin{array}{l}\text { Protein Phosphatase } 3 \\
\text { Regulatory Subunit } \mathrm{B} \alpha\end{array}$ & unknown & unknown & $\begin{array}{l}\text { regulatory subunit of calcineurin } \\
\text { calcium-dependent Calmodulin stimulated protein phosphatase }\end{array}$ \\
\hline UBE2H & $\begin{array}{l}\text { Ubiquitin Conjugating } \\
\text { Enzyme E2H }\end{array}$ & yes & unknown & $\begin{array}{l}\text { protein metabolism } \\
\text { Class I MHC mediated antigen processing and presentation } \\
\text { hypoxia-related gene }\end{array}$ \\
\hline YWHAH & $\begin{array}{l}\text { Tyrosine } 3 \text { Monooxygenase } \\
\text { / Tryptophane } 5 \text { Mono- } \\
\text { oxygenase, } \\
\text { Activation Protein Eta }\end{array}$ & yes & unknown & $\begin{array}{l}\text { binding and adaptor protein } \\
\text { kinase activity } \\
\text { telomerase activity }\end{array}$ \\
\hline YWHAZ & $\begin{array}{l}\text { Tyrosine } 3 \text { Monooxygenase } \\
\text { / Tryptophane } 5 \text { Mono- } \\
\text { oxygenase, } \\
\text { Activation Protein Zeta }\end{array}$ & yes & yes & $\begin{array}{l}\text { binding and adaptor protein } \\
\text { phospholipase activity } \\
\text { catalytic activity } \\
\text { MAP kinase activity }\end{array}$ \\
\hline NPTN & Neuroplastin & yes & unknown & $\begin{array}{l}\text { DNA and protein binding } \\
\text { kinase activity }\end{array}$ \\
\hline LDLTAP1 & $\begin{array}{l}\text { Low Density Lipoprotein } \\
\text { Receptor, } \\
\text { Adaptor Protein } 1\end{array}$ & yes & unknown & $\begin{array}{l}\text { protein and receptor binding } \\
\text { catalytic activity }\end{array}$ \\
\hline CAPZA2 & $\begin{array}{l}\text { Capping Actin Protein of } \\
\text { Muscle } \\
\text { Z-Line Subunit Alpha } 2\end{array}$ & yes & yes & $\begin{array}{l}\text { protein and receptor binding } \\
\text { ATP binding } \\
\text { Actin binding } \\
\text { telomerase activity }\end{array}$ \\
\hline
\end{tabular}




\begin{tabular}{|c|c|c|}
\hline \multicolumn{3}{|c|}{ Table 2} \\
\hline \multicolumn{3}{|c|}{ Patients and tumor pathological characteristic of the study population } \\
\hline \multirow[t]{2}{*}{ Patients and tumor characteristics } & Exosome genes & Microvesicle genes \\
\hline & $\mathrm{N}(\%)$ & $\mathrm{N}(\%)$ \\
\hline \multicolumn{3}{|l|}{ Gender } \\
\hline Male & $12(60.0)$ & $8(40.0)$ \\
\hline Female & $8(40.0)$ & $12(60.0)$ \\
\hline (Male/Female) & 1.5 & 0.6 \\
\hline Median age, years (Range) & 59 years $(29-81)$ & 59 years $(31-81)$ \\
\hline$\leq$ Median age & $12(60.0)$ & $12(60.0)$ \\
\hline >Median age & $8(40.0)$ & $8(40.0)$ \\
\hline \multicolumn{3}{|l|}{ Tumor grade } \\
\hline Low & $11(55.0)$ & $16(80.0)$ \\
\hline High & $8(45.0)$ & $4(20.0)$ \\
\hline \multicolumn{3}{|l|}{ Nodal stage } \\
\hline Yes & $6(30.0)$ & $7(35.0)$ \\
\hline No & $14(70.0)$ & $13(65.0)$ \\
\hline \multicolumn{3}{|l|}{ Primary tumor (PT) stage } \\
\hline pT1 & $2(10.0)$ & $0(0.0)$ \\
\hline pT2 & $8(40.0)$ & $12(60.0)$ \\
\hline рT3 & $6(30.0)$ & $8(40.0)$ \\
\hline PT4 & $4(20.0)$ & $0(0.0)$ \\
\hline Total (N) & 20 & 20 \\
\hline
\end{tabular}




\section{Table 3}

The association between tumor exosome genes mRNA expression and clinicopathological parameters of colorectal cancer (CRC) samples ( $P$ value, Pearson's $\chi 2$ test)

\begin{tabular}{|c|c|c|c|c|c|c|}
\hline \multirow[t]{2}{*}{$\begin{array}{l}\text { Patients and tumor } \\
\text { characteristics }\end{array}$} & \multirow{2}{*}{$\begin{array}{l}\text { Total } \\
\text { samples } \\
N(\%)\end{array}$} & \multicolumn{2}{|c|}{$\begin{array}{l}\text { PDGFA mRNA } \\
\text { expression } \\
\left(\begin{array}{l}\text { Cut off }=5.95) \mathrm{N} \\
(\%)\end{array}\right.\end{array}$} & \multirow{2}{*}{$\begin{array}{l}P \text { - } \\
\text { value }\end{array}$} & \multicolumn{2}{|c|}{$\begin{array}{l}\text { RAF1 mRNA } \\
\text { expression } \\
\left(\begin{array}{l}\text { Cut off }=1.5) \mathrm{N} \\
(\%)\end{array}\right.\end{array}$} \\
\hline & & $\begin{array}{l}\text { Low }(\leq \\
5.95)\end{array}$ & $\begin{array}{l}\text { High } \\
(>5.95)\end{array}$ & & $\begin{array}{l}\text { Low } \\
1.50)\end{array}$ & $\begin{array}{l}\text { High (> } \\
1.50)\end{array}$ \\
\hline CRC patients & 20 & $\begin{array}{l}10 \\
(50.0)\end{array}$ & $\begin{array}{l}10 \\
(50.0)\end{array}$ & & $\begin{array}{l}10 \\
(50.0)\end{array}$ & $\begin{array}{l}10 \\
(50.0)\end{array}$ \\
\hline
\end{tabular}

Gender

Male

$12(60.0) \quad 7(35.0) \quad 5(25.0)$

$7(35.0) \quad 5(25.0)$

Female

$8(40.0)$

$3(15.0)$

$5(25.0)$

$0.210 \quad 3(15)$

$5(25.0)$

0.210

(Male/Female)

1.5

2.3

1

2.3

1

Median age 59, years

$(29-81)$

$\leq$ Median age

$\begin{array}{llllll}12(60.0) & 6(30.0) & 6(30.0) & 1.000 & 8(40.0) & 2(10.0)\end{array}$

0.050

$>$ Median age

$8(40.0) \quad 4(20.0) \quad 4(20.0)$

$2(10.0) \quad 8(40.0)$

Histological grade

Low

$11(55.0) \quad 6(30.0) \quad 5(25.0)$

0.264

$6(30.0)$

$5(25.0)$

0.507

High

$8(45.0) \quad 4(20.0) \quad 4(20.0)$

$4(20.0) \quad 4(20.0)$

\section{Nodal stage}

$\begin{array}{llllllll}\text { Yes } & 6(60.0) & 3(15.0) & 3(15.0) & 0.373 & 3(15.0) & 3(15.0) & 0.606 \\ \text { No } & 14(40.0) & 6(30.0) & 8(40.0) & & 6(30.0) & 8(40.0) & \end{array}$

\section{Primary tumor (PT)}

stage

pT1

pT2

$2(10.0) \quad 1(5.0) \quad 1(5.0) \quad 1(5.0) \quad 1(5.0)$

$\begin{array}{lllllll}8(40.0) & 4(20.0) & 4(20.0) & 0.813 & 4(20.0) & 4(20.0) & 0.454\end{array}$

pT3

$6(30.0) \quad 3(15.0) \quad 3(15.0) \quad 2(10.0) \quad 4(20.0)$

$4(20.0) \quad 2(10.0) \quad 2(10.0)$

$3(15.0) \quad 1(5.0)$ 


\section{PT4}

Page 25/33 


\section{Table 4}

The association between tumor microvesicle genes mRNA expression and clinicopathological parameters of colorectal cancer (CRC) samples ( $P$ value; Pearson's $\chi 2$ test)

\begin{tabular}{|c|c|c|c|c|c|c|}
\hline \multirow[t]{2}{*}{$\begin{array}{l}\text { Patients and tumor } \\
\text { characteristics }\end{array}$} & \multirow{2}{*}{$\begin{array}{l}\text { Total } \\
\text { samples } \\
\mathrm{N}(\%)\end{array}$} & \multicolumn{2}{|c|}{$\begin{array}{l}\text { PDGFA mRNA } \\
\text { expression } \\
\text { (Cut off }=0.22) \mathrm{N} \\
(\%)\end{array}$} & \multirow{2}{*}{$\begin{array}{l}P \text { - } \\
\text { value }\end{array}$} & \multicolumn{2}{|c|}{$\begin{array}{l}R A F 1 \mathrm{mRNA} \\
\text { expression } \\
\left(\begin{array}{l}\text { (Cut off }=0.10) \mathrm{N} \\
(\%)\end{array}\right.\end{array}$} \\
\hline & & $\begin{array}{l}\text { Low }(\leq \\
0.22)\end{array}$ & $\begin{array}{l}\text { High } \\
(>0.22)\end{array}$ & & $\begin{array}{l}\text { Low } \\
(\leq 0.10)\end{array}$ & $\begin{array}{l}\text { High } \\
(>0.10)\end{array}$ \\
\hline CRC patients & 20 & $\begin{array}{l}14 \\
(70.0)\end{array}$ & $6(30.0)$ & & $\begin{array}{l}14 \\
(70.0)\end{array}$ & $6(30.0)$ \\
\hline
\end{tabular}

Gender

$\begin{array}{llllllll}\text { Male } & 8(40.0) & 5(25.0) & 3(15.0) & & 6(30.0) & 2(10.0) & \\ \text { Female } & 12(60.0) & 9(45.0) & 3(15.0) & 0.500 & 8(40.0) & 4(20.0) & 0.690 \\ \text { (Male/Female) } & 0.6 & 0.5 & 1 & & 0.75 & 0.5 & \end{array}$

Median age 59, years

(31-81)

$\leq$ Median age

$>$ Median age

$\begin{array}{lllllll}12(60.0) & 10 & 5(25.0) & 1.000 & 10 & 1(5.0) & 1.000 \\ 8(40.0) & (50.0) & 1(5.0) & & (50.0) & 5(25.0) & \\ & 4(20.0) & & & 4(20.0) & \end{array}$

Histological grade

Low

$16(80.0)$

$115(25.0)$

(55.0)

High

$4(20.0)$

$3(15.0)$

$1(5.0)$

0.445

$11 \quad 5(25.0)$

(55.0)

$3(15.0)$

$1(5.0)$

0.560

Nodal stage

Yes

7 (35.0)

3 (15.0) $4(20.0)$

$2(10.0)$

$5(25.0)$

No

13(65.0)

$6(30.0)$

$7(35.0)$

0.498

$5(15.0)$

$8(45.0) \quad 0.500$

Primary tumor (PT)

stage

pT1

$0(0.0) \quad 0(0.0) \quad 0(0.0)$

$12(60) \quad 8(40.0) \quad 4(20.0)$ 

pT2
8 (40)
$6(30.0)$
$2(10.0)$
$6(30.0)$
$2(10.0)$
pT3
$0(0.0)$
$0(0.0)$
$0(0.0)$
0 (0.0)
$0(0.0)$

PT4

Figures

A

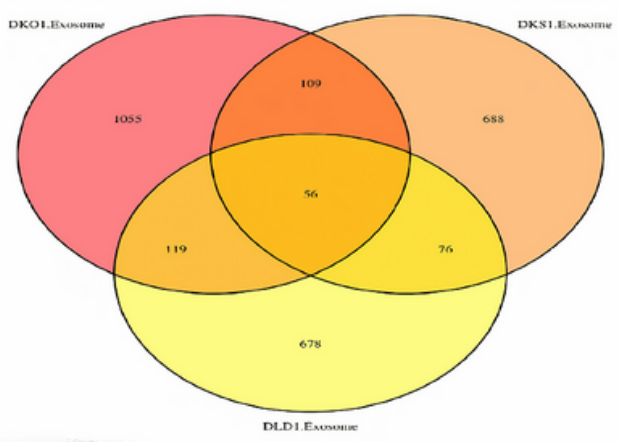

C

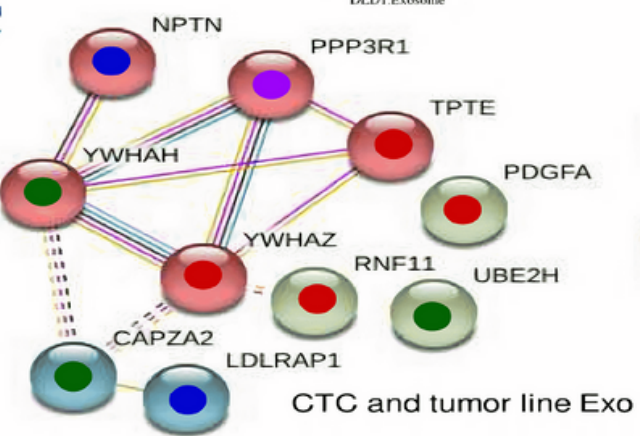

B

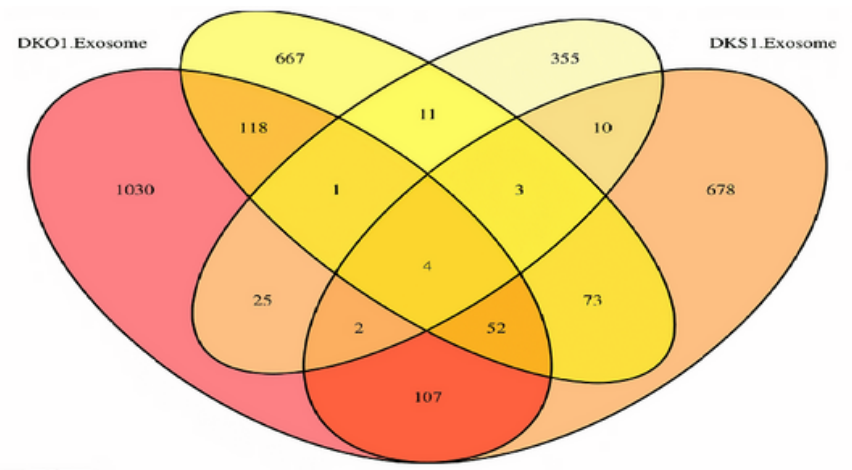

D

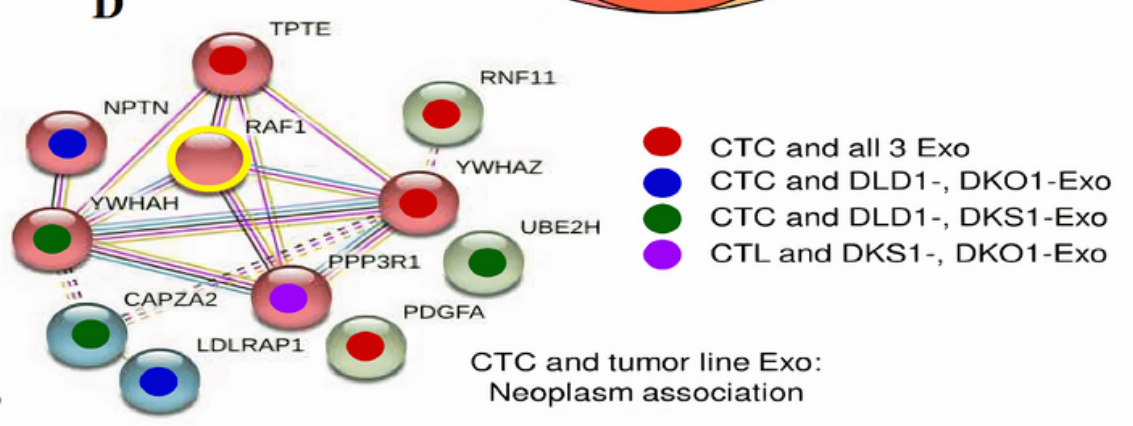

Figure 1

Distribution and protein-protein interaction network of genes in cell line-derived exosomes. (A)

Distribution of genes in cell line-derived exosomes from three cell lines, where 56 markers were expresses in all three-cell line-derived exosomes (intersection). (B) Ten markers are expressed in at least two cell line-derived TDEs and CTCs. (C) Network and enrichment analysis for these 10 protein coding genes according to String functional protein clusters (kmeans). The strength of interaction is indicated by the thickness of the connecting lines. Recovery in CTC and all 3 or 2 Exo preparations is indicated by a colored dot. The network shows significantly more interactions than expected ( $p$-value: 0.0156 ) (D) Network and enrichment analysis for these 11-tumor growth-associated protein coding genes according to String functional protein clusters (kmeans). The strength of interaction is indicated by the thickness of the connecting lines. Recovery in the $10 \mathrm{CTC}$ and 3 or 2 Exo preparations is indicated by a colored dot. The central node is RAF1 (yellow circle). The network shows significantly more interactions than expected (p-value: 0.00639). 

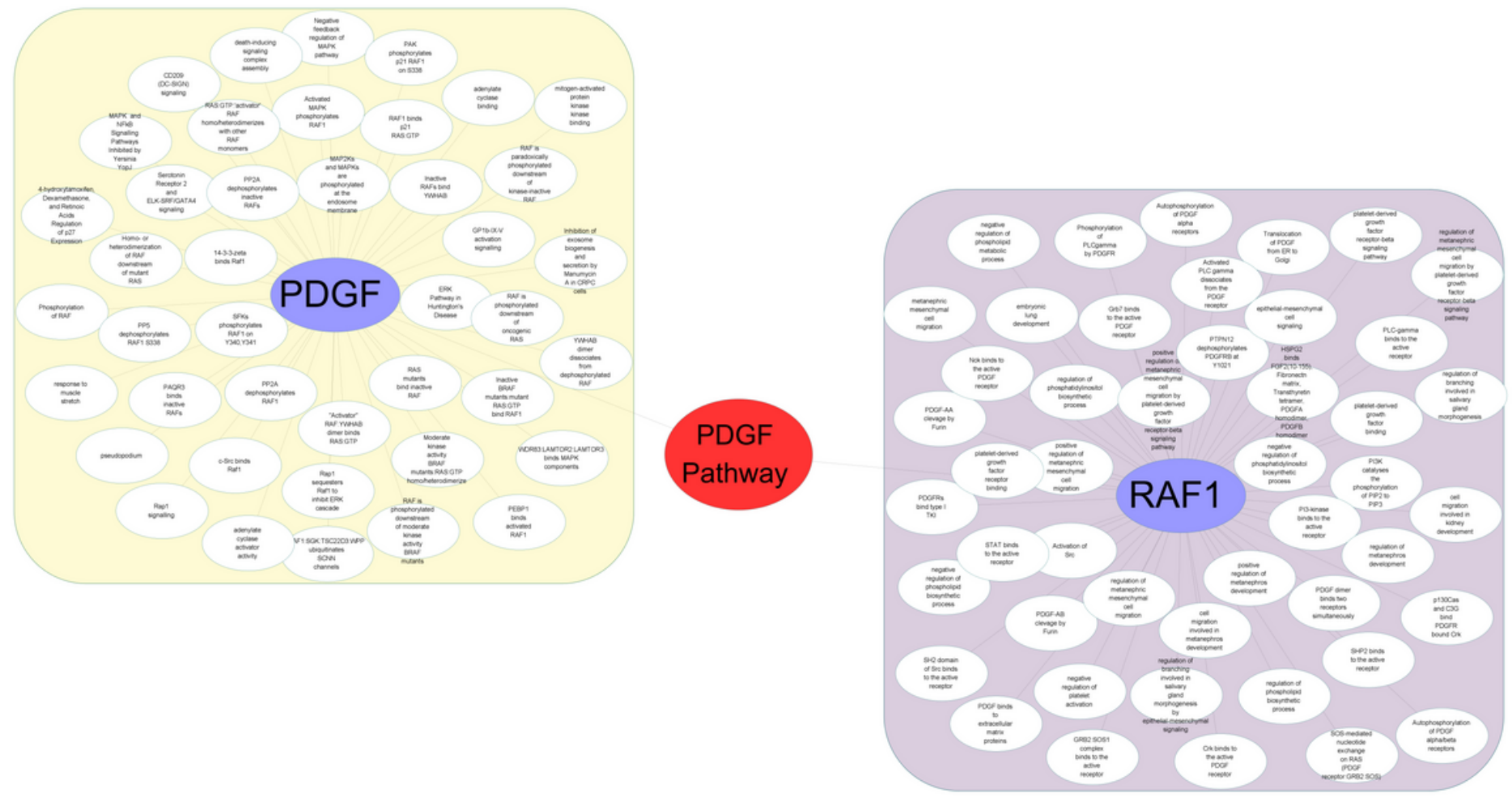

Figure 2

Pathway analysis using ClueGO plugin (Cytoscape) for PDGFA and RAF1. Pathway analysis indicated that PDGF Pathway is in common of both. 

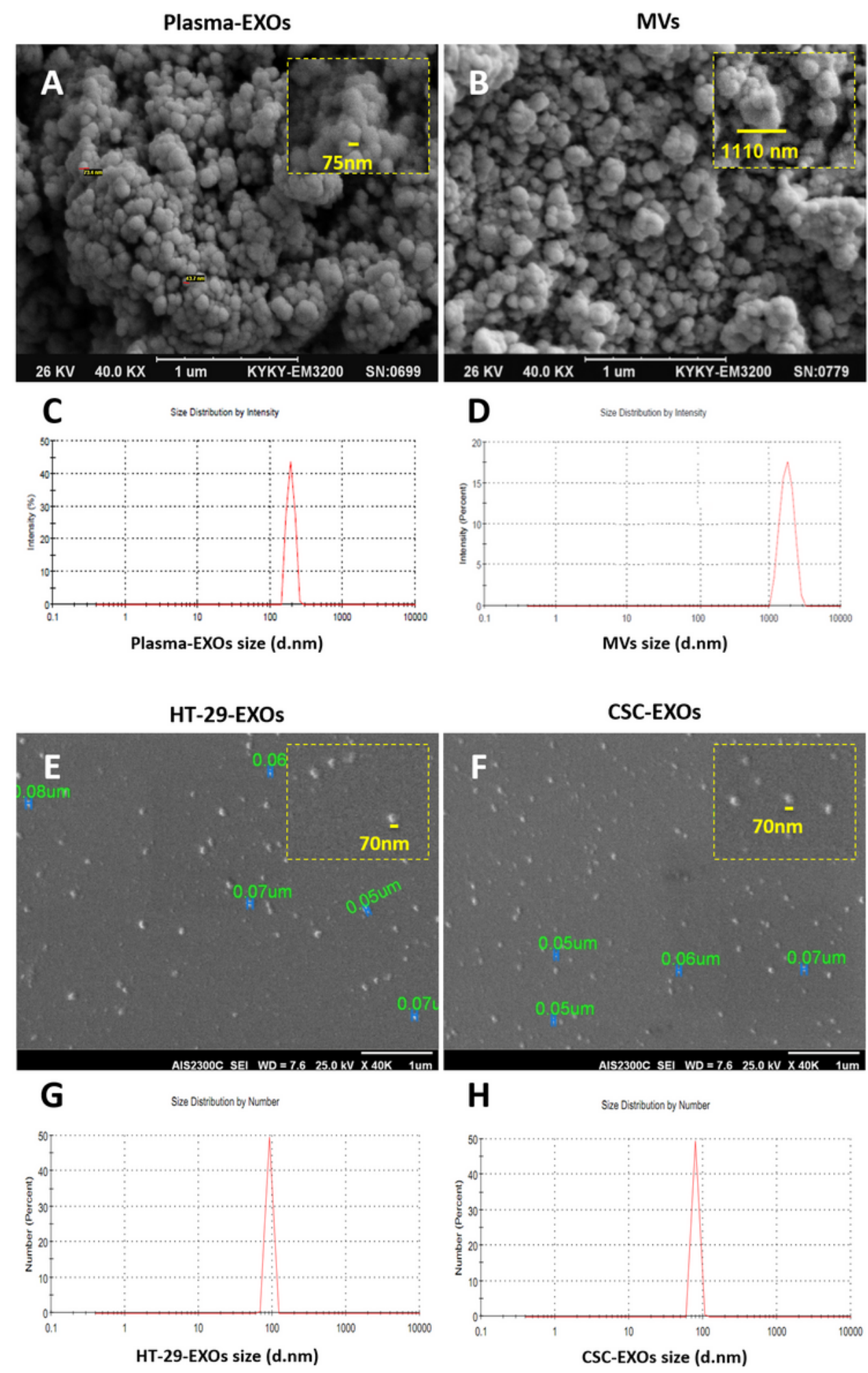

\section{Figure 3}

Exosome characterization. Representative SEM photograph of (A) plasma-EXOs and (B) MVs show homogenous round morphology. Exosome size distribution analysis of (C) plasma-EXOs and (D) MVs by DLS. Representative SEM photograph of (E) HT-29-EXOs and (F) CSC-EXOs. Exosome size distribution analysis of (G) HT-29-EXOs and (H) CSC-EXOs by DLS. Data are represented as mean \pm SD ( $n=3$ each). 


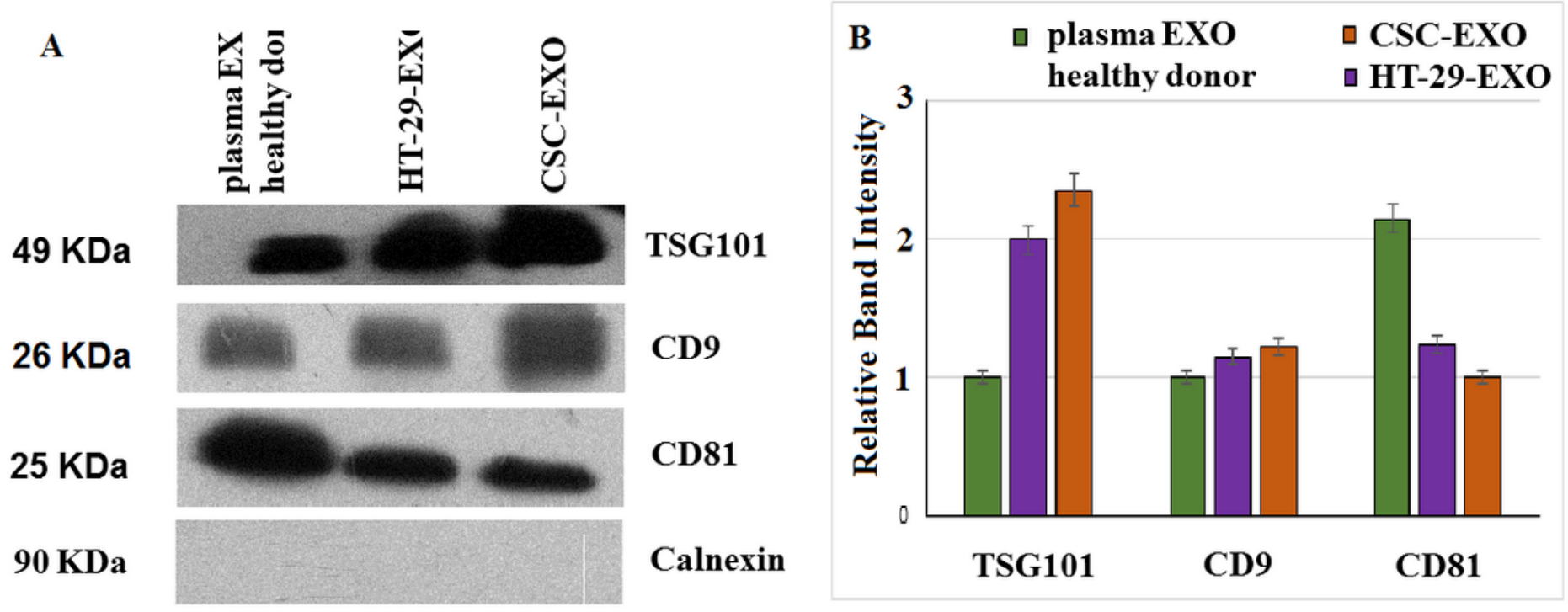

Figure 4

Western blot analysis of exosome surface marker expression. (A)_Expression of TSG101, CD9, CD81 and, as a negative control calnexin, were evaluated by WB in plasma EXOs, CSC-EXOs, and HT-29-EXOs to confirm the exosomal characteristic of isolated exosomes. (B) The relative expression levels of exosomal markers of plasma EXOs, CSC-EXOs, and HT-29- EXOs. Data are represented as mean $\pm \operatorname{SD}(n=3)$.

A

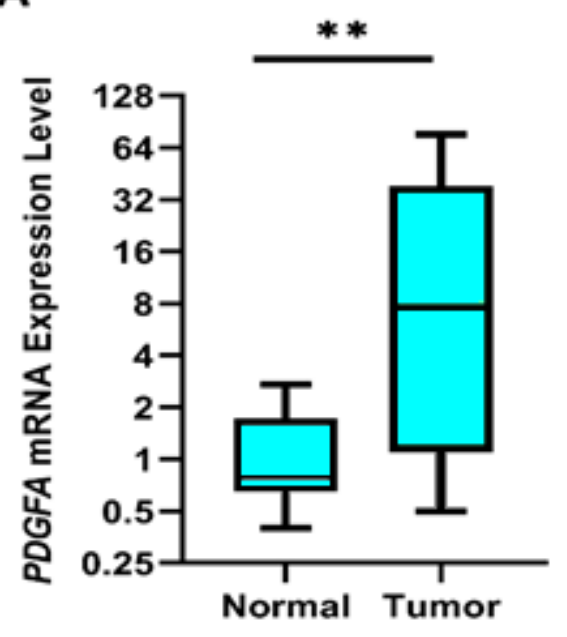

TDEs

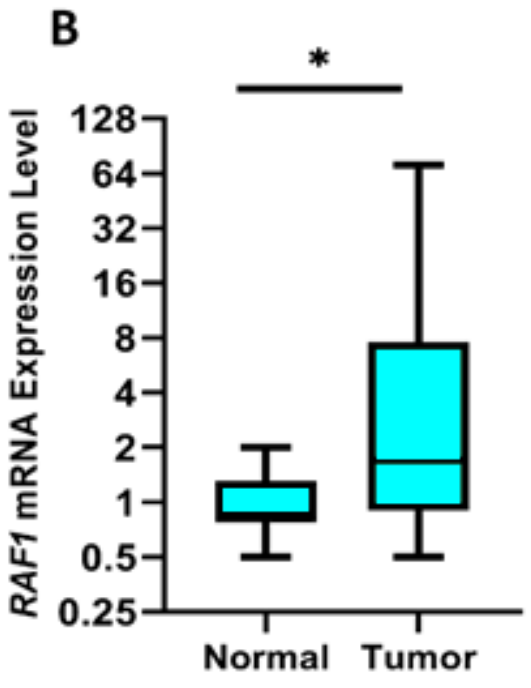

TDEs

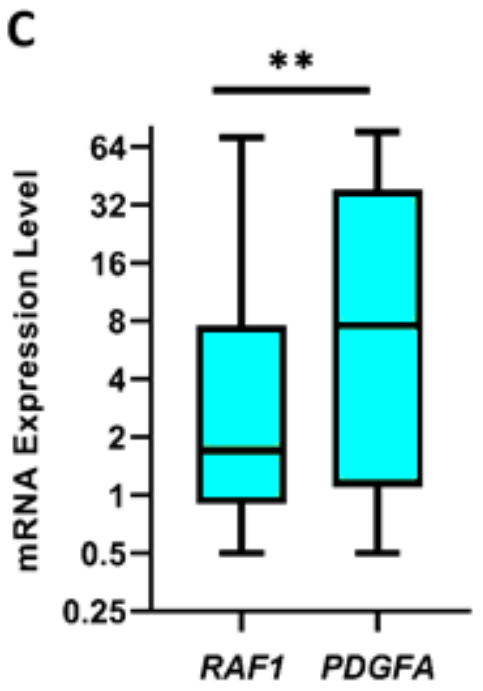

TDES

Figure 5 
Real-time PCR analysis of PDGFA and RAF1 expression levels in TDEs. TDEs from CRC patients revealed a statistically significant differences between (A) median mRNA expression levels of PDGFA $(P=0.0086)$ and (B) RAF1 ( $P=0.048)$ compared to healthy control samples. (C) A statically significant positive correlation was observed between PDGFA and RAF1 mRNA expression patterns in TDEs $(P=0.0084)$. Data are represented as mean $\pm \mathrm{SD}(n=3) .{ }^{\star} P<0.05$ and ${ }^{\star} * P<0.01$.

A

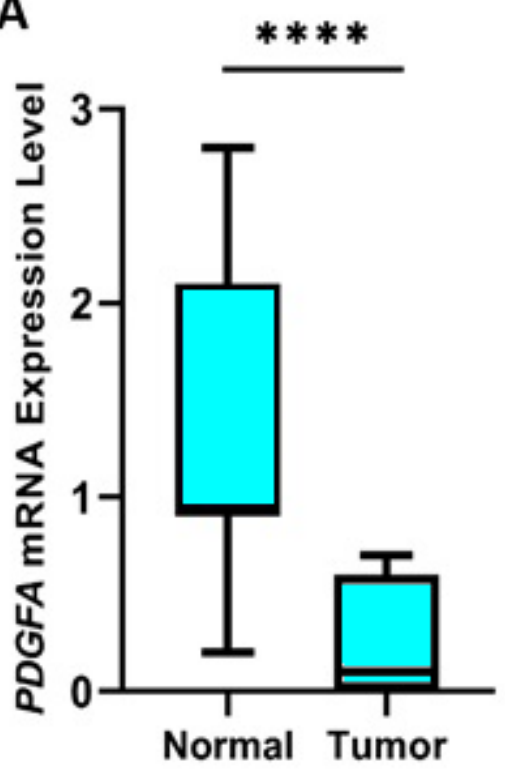

MVs
B

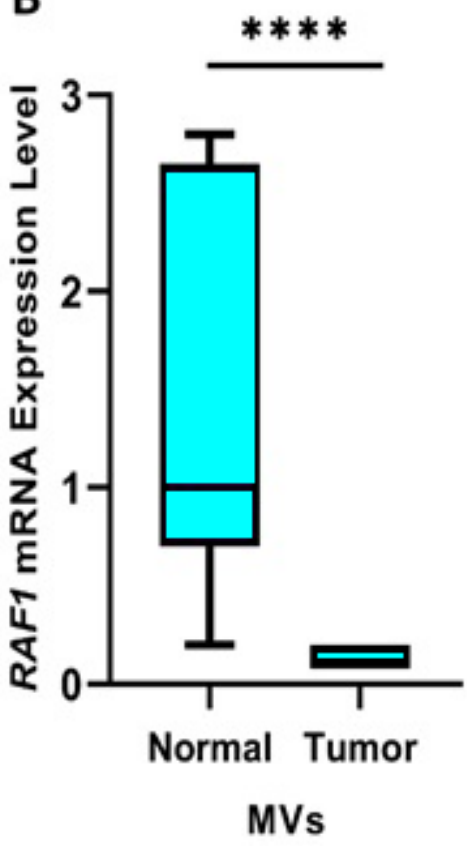

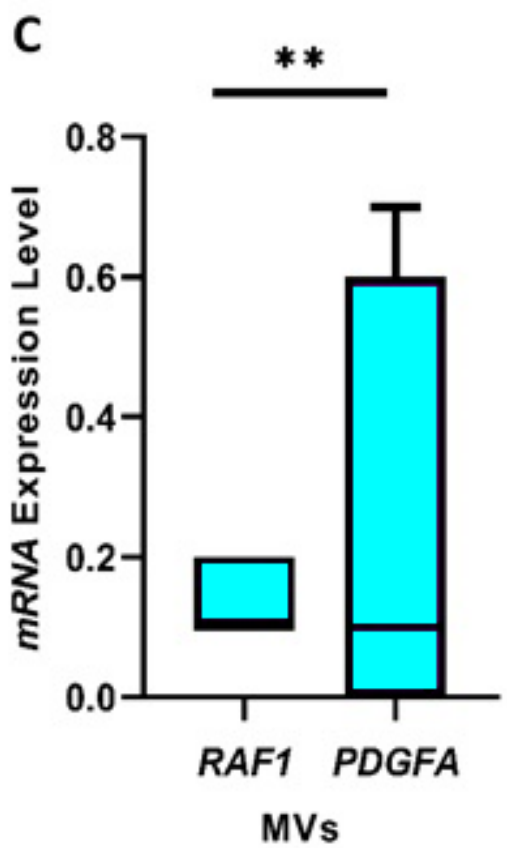

Figure 6

Real-time PCR analysis of PDGFA and RAF1 expression levels in MVs. MVs from CRC patients showed a statistically significant decrease in (A) median mRNA expression levels of PDGFA ( $P=0.0001)$ and $(\mathbf{B})$ $R A F 1$ ( $P=0.0001)$ compared to healthy control samples (C) A statically significant positive correlation was found between mRNA PDGFA and RAF1expression patterns in MVs $(P=0.0084)$. Data are represented

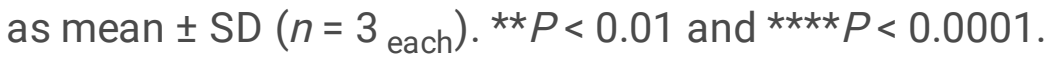



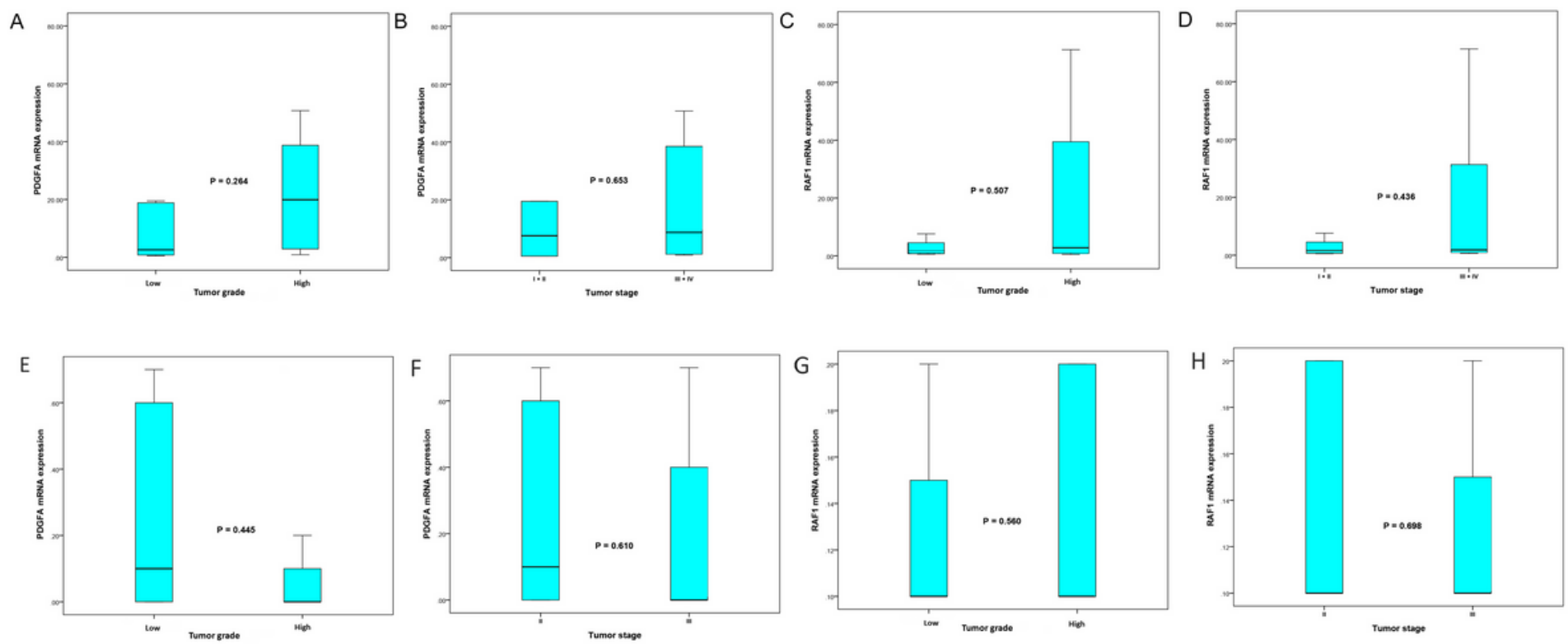

Figure 7

Box plot analysis of expression levels of tumor exosomes and tumor microvesicles in tumor grade low versus high and tumor stage I+II versus III+IV of colorectal cancer (CRC) patients using Mann-Whitney $U$ test. (A), (B) The results showed that there are no statistically significant associations for median expression levels of PDGFA mRNA between tumor differentiation (low) versus (high) and tumor stage (I+II) versus (III+IV) $(\mathrm{P}=0.264, \mathrm{P}=0.653$, respectively), and also (C) (D) median expression levels of $R A F 1$ mRNA between tumor differentiation (low) versus (high) and tumor stage (I+II) versus (III+IV) $(P=0.507$, $P=0.436$, respectively) in CRC patients. $(E),(F)$ The results revealed that there are no statistically significant associations for median expression levels of PDGFA mRNA between tumor differentiation (low) versus (high) and tumor stage II versus III ( $P=0.445, P=0.610$, respectively), and also (G), (H) median expression levels of RAF1 mRNA between tumor differentiation (low) versus (high) and tumor stage II versus III ( $P=0.560, P=0.698$, respectively) in CRC cases. Based on the standard definitions, each box-plot shows the median (bold line) and interquartile lines (box). Data are represented as mean \pm $\mathrm{SD}(\mathrm{n}=3)$. Though no significant differences in the median level of PDGFA and RAF1 mRNA expression in tumor exosomes of different grades or stages were seen, these results should be considered with caution taking into account the small numbers of samples. 

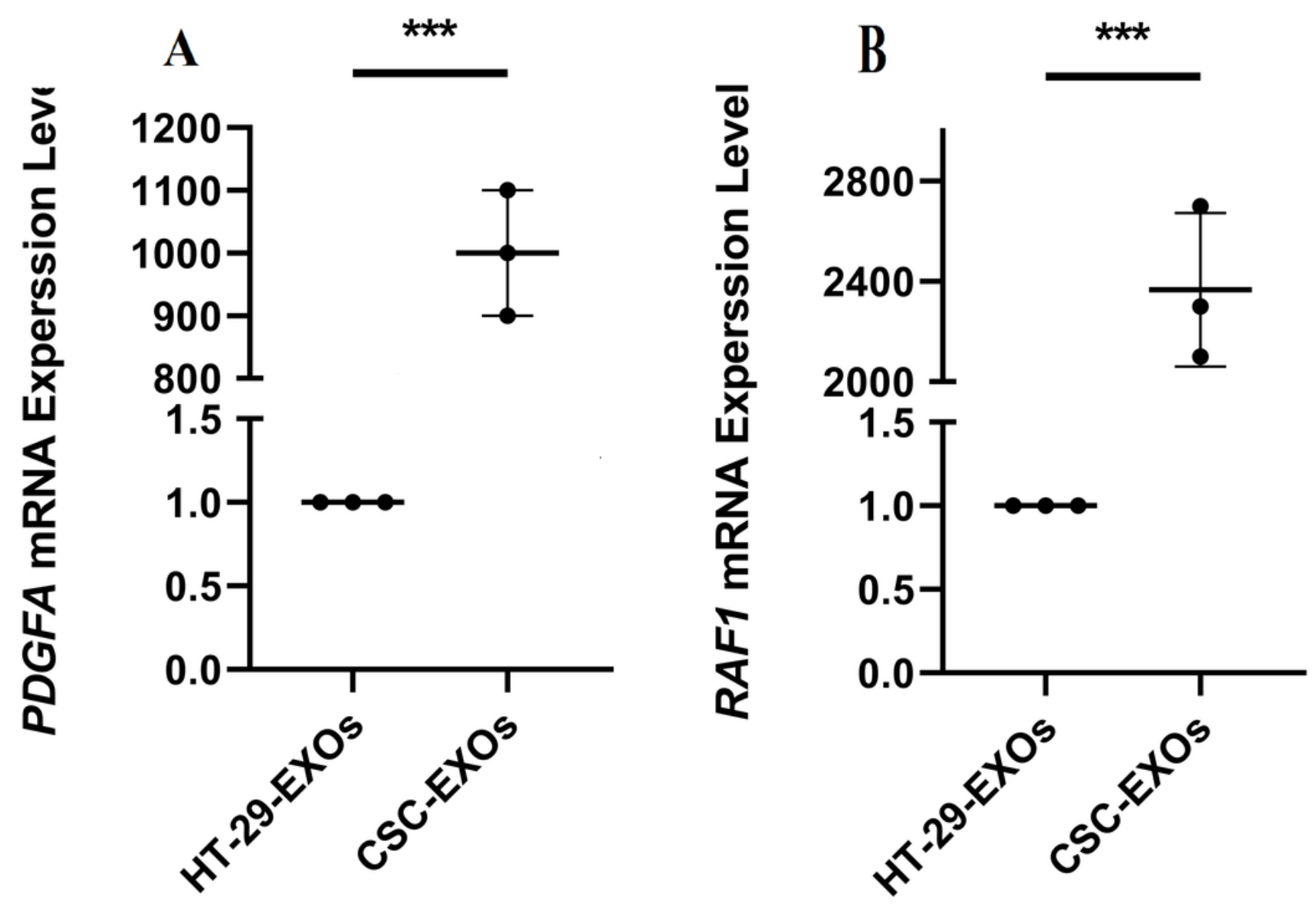

Figure 8

Real-time PCR analysis of PDGFA and RAF1 expression levels in CSC-EXOs compared to HT-29-EXOs. CSC-EXOs showed significantly increased expression of (A) PDGFA ( $P=0.0004)$ and (B) RAF1 $(P=0.0004)$ compared to HT-29-EXOs. Data are represented as mean $\pm \mathrm{SD}(\mathrm{n}=3)$. ${ }^{\star \star \star} P<0.001$.

\section{Supplementary Files}

This is a list of supplementary files associated with this preprint. Click to download.

- supplementaryfigure1.tif

- supplementarytable1.xlsx

- supplementarytable2.xlsx

- supplementarytable3.xlsx

- supplementarytable4.xlsx

- SupplementaryTable5.xlsx 